\title{
Precision and accuracy of Dahl-Lea back-calculated smolt lengths from adult scales of
}

\author{
Atlantic salmon Salmo salar
}

\author{
N.N. HANSON ${ }^{1}$ | G.W. SMITH ${ }^{1}$ | S.J. MIDDLEMAS ${ }^{1}$ | C.D. TODD ${ }^{2}$ \\ ${ }^{1}$ Marine Scotland Science, Salmon and Freshwater Fisheries Laboratory, Pitlochry, UK \\ ${ }^{2}$ Scottish Oceans Institute, University of St Andrews, St Andrews, UK \\ Correspondence \\ N.N. Hanson, Marine Scotland Science, Salmon and Freshwater Fisheries Laboratory, Pitlochry \\ PH16 5LB, UK \\ Email: nora.hanson@gov.scot
}

Using tagged and recaptured Atlantic salmon Salmo salar $(\mathrm{n}=106)$ the present analysis shows that the most commonly applied linear back-calculation method for estimating past length, the Dahl-Lea method, resulted in overestimation of the length of large smolts and underestimation of small smolts. A correction equation $(y=0.53 x+6.23)$ for estimating true smolt length $(y)$ from lengths back-calculated from adult scale measures $(x)$ to account for these systematic discrepancies is proposed.

\section{KEYWORDS}

allometry, back-calculation, circuli; growth, increment analysis, Salmo salar

This article has been accepted for publication in the Journal of Fish Biology and undergone full peer review but has not been through the copyediting, typesetting, pagination and proofreading process, which may lead to differences between this version and the Version of Record. Please cite this article as doi: 10.1111/jfb.13863 
Longitudinal measures of individual growth histories are essential for the interpretation of variability in successful life histories. At the population level, measures of growth history permit interrogation of the relationship between growth and survival of salmonids across differing life stages and the probable environmental factors influencing growth at those times (Friedland et al., 2000; Peyronnet et al., 2007). Individual growth histories of teleosts have been inferred from patterns of incremental scale growth, manifest as the formation of distinct ridges, or circuli, in the calcified part of the scale (Casselman, 1990). In many species, somatic growth in length is demonstrably correlated with scale growth because the scales increase in size, but not number, as the fish grows. This correlation potentially enables back-calculation of length at age from scale measurements if the length of the fish at capture is known.

Conventionally, growth histories of Atlantic salmon Salmo salar L. 1758 have been inferred from back-calculated lengths generated by the Dahl-Lea method, which assumes a simple linear isometry between scale radius and body length throughout the life of the individual fish (Shearer, 1992). This method was considered generally reliable for back-calculation of body length increase during the marine migration (Shearer, 1992). However, given the marked shift in growth rate at the transition between the juvenile (fresh water) and sub-adult-adult (marine) phases, it is likely that there are also similarly marked changes in scale-length allometry at that transition in the individual's life history (Lindroth, 1963; Tremblay \& Giguère, 1992). While there are known to be inaccuracies in applying simple back-calculations, such as the Dahl-Lea method (Heidarsson et al., 2006), they continue to be used to estimate salmonid growth over the marine phase (Friedland et al., 2000; Kuparinen et al., 2009; Todd et al., 2012). 
The purpose of the present analysis was to provide an empirical assessment of the accuracy and precision of the Dahl-Lea method within a subsample of adult $S$. salar tagged and measured as emigrant smolts and recaptured at their migratory return to the River North Esk, a major S. salar river in eastern Scotland, UK. A full exploration of the body-to-scale relationship across a wide range of $S$. salar ages and sizes is beyond the scope of the present study ( for alternatives to back-calculation see Friedland et al., 2009; Jensen et al., 2012; for more empirical data see Lindroth, 1963). Rather, estimates of variability in back-calculated values and a simple equation to correct smolt lengths back-calculated using the Dahl-Lea equation are provided.

Between 1982 and 2010, S. salar smolts emigrating from the River North Esk were intercepted in a diversionary lade trap near the head of tide $\left(56.75^{\circ} \mathrm{N}, 2.45^{\circ} \mathrm{W}\right)$. Fork length $\left(L_{\mathrm{F}}\right)$ was recorded to the nearest $0.5 \mathrm{~cm}$ (rounded down) prior to 2000 and to the nearest $0.1 \mathrm{~cm}$ thereafter. Individual smolts were uniquely tagged and the adipose-fin clipped to aid their identification as return adults [for details, see Friedland et al. (2000) and Todd et al. (2012)]. Adults were recaptured in commercial net fisheries in or adjacent to the river mouth. Fork length was recorded to $0.5 \mathrm{~cm}$ (rounded down) and mass to the nearest $0.1 \mathrm{~kg}$. A sample of scales from the standard region (left-hand side of the fish, 3-6 rows above the lateral line and posterior to the dorsal fin; Shearer, 1992) was removed for further analysis. Scales from a subsample of recaptured adults were available for the present analysis.

A total of 247 scales from 67 adult one sea-winter (1SW) and 132 scales from 39 adult two sea-winter (2SW) S. salar tagged as smolts were retrieved for growth increment analysis. Commonly, a single scale is used in $S$. salar population studies to back-calculate length at age from an individual fish of known capture length. In the present analysis all scales from each individual that showed no evidence of significant replacement at the parr stage or of marginal 
erosion were measured, resulting in 1-7 scales measured per individual. Scales were aged and measurements of annuli and the beginning of marine growth were made using standard methods (Shearer, 1992). Back-calculated smolt lengths varied among scales within an individual; furthermore, rounding down of the observed (i.e., true) smolt length by $0.5 \mathrm{~cm}$ introduced an error of between 3-5\% across the range of smolt lengths. To incorporate these sources of uncertainty into the analysis a bootstrap approach was adopted. The dataset was randomly resampled choosing one observation per individual. Error in smolt $L_{\mathrm{F}}$ that were rounded down was accounted for by adding to the observed length a value sampled randomly from a uniform distribution $(0-0.5 \mathrm{~cm})$. This process was repeated 1000 times and the following statistical analyses were performed on each resampled data set comprising a single scale measurement from 106 individual S. salar. All statistical analyses were performed in R 3.4.3 (www.rproject.org) using the lme4 (Bates et al., 2015, 4), tidyverse (Wickham, 2017) and broom packages (Robinson, 2018).

Smolt $L_{\mathrm{F}}$ was back-calculated from scale measurements of the adult fish using the DahlLea method (Francis, 1990): $\left[L_{i}=S_{i}\left(S_{c}\right)^{-1}\right] L_{c}$, where $L$ and $S$ refer to the body length of the fish and to the scale radius, respectively. The subscript $i$ refers to length at a feature of interest, $i$ (here, the beginning of marine growth period) and the subscript $c$ refers to $L_{\mathrm{F}}$ at capture. Absolute error in back-calculated lengths was calculated (i.e., accuracy $=$ absolute difference between observed and back-calculated lengths) and age-related effects on accuracy were explored using generalised linear regression models with $\gamma$-error distribution and a log link. Because body-scale allometry is known to be affected by growth rates (Casselman, 1990; Francis, 1990), both river age (1-4 years) and sea age (1 or 2 years) were included as categorical covariates to test age effects on accuracy of back-calculation. The effects of sea and river ages 
were tested by fitting a candidate set of models that included a null (intercept-only) model, additive effects and interactions between age covariates and back-calculated lengths. For each iteration the model with the lowest second order Akaike information criterion (AICc; Burnham \& Anderson, 2002) value was recorded and the proportion of times each model was selected among the 1000 iterations was recorded. Precision of the Dahl-Lea method was summarised by the mean CV in absolute error of back-calculated smolt lengths from each re-sampled dataset. Individual-level precision was the CV of error across re-sampled data within an individual fish.

To improve the accuracy of future smolt $L_{\mathrm{F}}$ back-calculations from adult $S$. salar scales, a correction equation from the re-sampled datasets was derived by ordinary least-squares regression of observed smolt $L_{\mathrm{F}}(\mathrm{cm})$ against that back-calculated from the recaptured adult. The additional possible effects of sea and river age on the observed smolt $L_{\mathrm{F}}$ were explored using AIC model selection in the manner described above. The applicability of correction equations to scale measurements for other $S$. salar within the River North Esk was investigated by comparing the distribution of smolt $L_{\mathrm{F}}$ from large samples of smolts emigrating from the North Esk system during 2001-2011 with the distribution of back-calculated smolt $L_{\mathrm{F}}$ from returning adults that emigrated in those same years. Because natural size-selective mortality affecting differences in emigrant and returning adult smolt $L_{\mathrm{F}}$ cannot be excluded, this assessment was restricted to a visual assessment that the distribution of corrected back-calculated smolt $L_{\mathrm{F}}$ (from adult scales) conformed more closely to that of emigrant smolts than did the uncorrected Dahl-Lea backcalculations.

Accuracy in back-calculation of smolt $L_{\mathrm{F}}$ was not dependent on sea age or river age (the null model had a minimum value of AICc for $87 \%$ of iterations $).$ Mean absolute error was \pm 0.9 $\mathrm{cm}(95 \%$ CI: $0.8-1.0 \mathrm{~cm})$, or $c .7 \%$, which was of similar magnitude to the error found by 
Heidarsson et al. (2006) for S. salar from Iceland. However, unlike the samples of Heidarsson et al. (2006), the North Esk samples showed systematic bias in Dahl-Lea length back-calculations: the $L_{\mathrm{F}}$ of larger smolts was overestimated and smaller smolts were underestimated, with this effect increasing at the extremes of true smolt $L_{\mathrm{F}}$. This pattern can be described also by the residuals from the regression of observed smolt $L_{\mathrm{F}}$ on back-calculated smolt $L_{\mathrm{F}}$ (Figure 1a), but is largely accounted for by the correction equation proposed below.

The mean CV of absolute error in Dahl-Lea back-calculations was 76.2\% (95\% CI: 76.076.5\%). Within individual fish, the mean $\mathrm{CV}$ of error in back-calculated smolt $L_{\mathrm{F}}$ was $45 \%$ (95\% CI: 40-50\%), indicating differing scale-body proportionality among scales taken from the recommended body region. The relationship between observed smolt $L_{\mathrm{F}}$ and back-calculated smolt $L_{\mathrm{F}}$ did not differ between river or sea-age classes. A model that included only backcalculated length to predict observed length most frequently had the minimum AICc in the candidate set (70\% of iterations). Linear equations to predict the mean true smolt $L_{\mathrm{F}}$ from DahlLea back-calculated lengths were derived from each of the 1000 re-sampled datasets (Figure 1a). The mean parameter estimates (95\% C.I.) were: $L_{\mathrm{Fsmolt}}=0.53(0.50-0.57)\left(S_{c} S_{c}{ }^{-1}\right) L_{c}+6.23(5.76$ - 6.64), where $L_{\mathrm{Fsmolt}}$ was the observed smolt $L_{\mathrm{F}}(\mathrm{cm}), S_{i}$ was scale radius at smolt emigration, $S_{c}$ was scale radius at capture and $L_{c}$ was salmon $L_{\mathrm{F}}(\mathrm{cm})$ at capture. The Dahl-Lea method historically has been used to calculate smolt length from the scales of adults returning to the River North Esk (Friedland et al., 2000; Todd et al., 2012). When compared with the distribution and range of emigrant smolt lengths observed over multiple years for that river catchment, the inaccuracies of Dahl-Lea back-calculation at both the lower and upper margins of the distribution were apparent. However, the distribution and range of smolt lengths obtained by 
correcting back-calculated lengths using the equation derived here clearly were more comparable with observed emigrant smolt datasets than were the uncorrected Dahl-Lea estimates (Figure 1b).

The relationship between scale growth, somatic growth and time at sea in $S$. salar is complex (Todd et al., 2013). An extension of the work initially undertaken by Lindroth (1963), exploring in detail the scale- $L_{\mathrm{F}}$ relationship and applied to a wide range of size and river-age and sea-age classes, would help to validate or refute the hypotheses implicit in various backcalculation methods (Francis, 1990). In the absence of such data, and of detailed capture-tagrecapture information for large samples of salmon for a given river system, simple correction applied to the Dahl-Lea method is recommended.

The use of back-calculated lengths from the Dahl-Lea method is common in studies where estimates of size at age are required ecological variables (Kuparinen et al., 2009; Fjørtoft et al., 2014; Izzo \& Zydlewski, 2017). However, the present results, together with other studies (Heidarsson et al. 2006) highlight that $S$. salar ecologists and managers should be aware of the (im)precision and potential inaccuracies of inferred growth metrics and qualify their conclusions when selecting and interpreting models including covariates based on back-calculated lengths. Quantitative differences in the relationship between back-calculation error and observed smolt size for different salmonid stocks may arise from factors affecting the validity of the backcalculation method; these possibilities include differences in overall freshwater growth rate, or the incidence of short-term and rapid spring freshwater growth immediately prior to smolt emigration [i.e., run-out (Francis, 1990; Heidarsson et al., 2006)]. These possibilities require further consideration. However, the present analytical method, which incorporates into the estimates multiple sources of uncertainty (including measurement error and sampling error), does 
provide an informed preliminary approach for validating growth history estimation from other taxa and growth structures.

\section{ACKNOWLEDGEMENTS}

The authors thank the many colleagues, past and present, involved in data collection. The authors are also grateful to T. Mendo for comments on an early draft of the manuscript.

\section{REFERENCES}

Bates, D., Mächler, M., Bolker, B. \& Walker, S. (2015) Fitting Linear Mixed-Effects Models Using lme4. Journal of Statistical Software, Articles 67, 1-48.

Burnham, K. P. \& Anderson, D. R. (2002) Model Selection and Multimodel Inference: A Practical Information-Theoretic Approach. Springer.

Casselman, J. M. (1990) Growth and relative size of calcified structures of fish. Transactions of the American Fisheries Society 119, 673-688.

Dietrich, J. P. \& Cunjak, R. A. (2007) Body and scale growth of wild Atlantic salmon smolts during seaward emigration. Environmental Biology of Fishes 80, 495-501.

Einum, S. (2002) Growth rate correlations across life-stages in female Atlantic salmon. Journal of Fish Biology 60, 780-784. 
Fjørtoft, H. B., Borgstrøm, R. \& Skaala, Ø. (2014) Differential changes in growth patterns of anadromous brown trout and Atlantic salmon from the River Etneelva over a 25-year period. Marine Biology Research 10, 301-307.

Francis, R. I. C. C. (1990) Back-calculation of fish length: a critical review. Journal of Fish Biology 36, 883-902.

Friedland, K. D., Hansen, L. P., Dunkley, D. A. \& MacLean, J. C. (2000) Linkage between ocean climate, post-smolt growth and survival of Atlantic salmon (Salmo salar L.) in the North Sea area. ICES Journal of Marine Science 57, 419-429.

Friedland, K. D., Moore, D. \& Hogan, F. (2009a) Retrospective growth analysis of Atlantic salmon (Salmo salar) from the Miramichi River, Canada. Canadian Journal of Fisheries and Aquatic Sciences 66, 1294-1308.

Friedland, K. D., MacLean, J. C., Hansen, L. P., Peyronnet, A. J., Karlsson, L., Reddin, D. G., Ó Maoiléidigh, N. \& McCarthy, J. L. (2009b) The recruitment of Atlantic salmon in Europe. ICES Journal of Marine Science 66, 289-304.

Heidarsson, T., Antonsson, T. \& Snorrason, S. S. (2006) The relationship between body and scale growth proportions and validation of two back-calculation methods using individually tagged and recaptured wild Atlantic Salmon. Transactions of the American Fisheries Society 135, 1156-1164.

Izzo, L. K. \& Zydlewski, J. (2017) Retrospective analysis of seasonal ocean growth rates of two sea winter Atlantic salmon in eastern Maine using historic scales. Marine and Coastal Fisheries 9, 357-372.

Jensen, A. J., Ó Maoiléidigh, N., Thomas, K., Einarsson, S. M., Haugland, M., Erkinaro, J., Fiske, P., Friedland, K. D., Gudmundsdóttir, A. K., Haantie, J., Holm, M., Holst, J. C., 
Jacobsen, J. A., Jensås, J. G., Kuusela, J., Melle, W., Mork, K. A., Wennevik, V. \& Østborg, G. M. (2012) Age and fine-scale marine growth of Atlantic salmon post-smolts in the Northeast Atlantic. ICES Journal of Marine Science 69, 1668-1677.

Kuparinen, A., Garcia de Leaniz, C., Consuegra, S. \& Merilä, J. (2009) Growth-history perspective on the decreasing age and size at maturation of exploited Atlantic salmon. Marine Ecology Progress Series 376, 245-252.

Lindroth, A. (1963) The body/scale relationship in Atlantic salmon (Salmo salar L.). A preliminary report. Journal du Conseil intenational pour l'Exploration de la Mer 28, $137-152$.

Peyronnet, A., Friedland, K. D., Maoiléidigh, N. ó, Manning, M. \& Poole, W. R. (2007) Links between patterns of marine growth and survival of Atlantic salmon Salmo salar, L. Journal of Fish Biology 71, 684-700.

Robinson, D. (2018) Broom: Convert Statistical Analysis Objects into Tidy Data Frames. R package. Available at https://cran.rproject.org/web/packages/broom/vignettes/broom.html

Shearer, W. M. (1992) Atlantic Salmon Scale Reading Guidelines. ICES Cooperative Report 188. Copenhagen: International Council for the Exploration of the Seas. 46.

Todd, C. D., Friedland, K. D., MacLean, J. C., Whyte, B. D., Russell, I. C., Lonergan, M. E. \& Morrissey, M. B. (2012) Phenological and phenotypic changes in Atlantic salmon populations in response to a changing climate. ICES Journal of Marine Science $\mathbf{6 9}$, $1686-1698$.

Todd, C. D., Whyte, B. D. M., MacLean, J. C., Revie, C. W., Lonergan, M. E. \& Hanson, N. N. (2013) A simple method of dating marine growth circuli on scales of wild one sea- 
winter and two sea-winter Atlantic salmon (Salmo salar). Canadian Journal of Fisheries and Aquatic Sciences 71, 645-655.

Tremblay, G. \& Giguère, L. A. (1992) Relation longueur/écaille allométrique chez le saumon atlantique (Salmo salar) durant la phase marine. Canadian Journal of Fisheries and Aquatic Science 49, 46-51.

Wickham, H. (2017) Tidyverse: Easily Install and Load the 'Tidyverse'. R package. Available at www.tidyverse.org 
Figure 1: Atlantic salmon Salmo salar scale back-calculation corrections. (a) Relationship between Dahl-Lea back-calculated smolt fork length $\left(L_{\mathrm{F}}\right)$ estimates and measured smolt $L_{\mathrm{F}}$ from tag recaptured fish on the River North Esk. $\bullet$, Median measurements from a single scale from each fish $(n=106)$ in the analysis; - , median fitted line; , 95\% credible intervals; --- , the 1:1 relationship. (b) Boxplots of Dahl-Lea back-calculated smolt $L_{\mathrm{F}}$ of adults returning to the River North Esk in the smolt years 2001 to 2011 ( $n=12,920$; median $L_{\mathrm{F}}=11.6 \mathrm{~cm}$, inter-quartile range $=2.6 \mathrm{~cm}$ ); Dahl-Lea estimates corrected by the application of the relationship derived from tag recapture data $(n=12,920$, median $=12.4 \mathrm{~cm}$, inter-quartile range $=1.4 \mathrm{~cm})$; observed smolt lengths in the same smolt year $(n=72,252$, median $=12.1 \mathrm{~cm}$, inter-quartile range $=1.5 \mathrm{~cm})$. 
